\title{
Control of reproductive growth in Puna chicory by grazing management
}

\author{
GUANGDI LI, P.D. KEMP and J. HODGSON \\ Plant Science Department, Massey University, Palmerston North
}

\section{Abstract}

The effect of reproductive stem removal on the growth and development of Grasslands Puna chicory (Cichorium intybus L.) was studied on the Deer Research Unit (DRU) and the Pasture and Crop Research Unit (PCRU) at Massey University in 1993-1994. The chicory was in its second and fourth years on the DRU and PCRU respectively. A medium grazing intensity with deer was used on the DRU and four grazing intensities were applied with sheep on the PCRU. Chicory accumulated $10007 \mathrm{~kg} \mathrm{DM} /$ ha herbage mass over 6 months from November to May on the DRU and it accumulated $4904 \mathrm{~kg} \mathrm{DM} / \mathrm{ha}$ herbage mass on the PCRU over the same period. The growth of primary reproductive stems was suppressed by grazing intensities that left less than $100 \mathrm{~mm}$ of stem stubble. None of the grazing intensities prevented the growth of secondary and axillary reproductive stems. Leaf mass accumulation over the season was greatest under very hard grazing $(0-50 \mathrm{~mm})$, whereas the total herbage (leaf and stem) mass was greatest under lax grazing (150-200 mm). The-primary-stems-produced-in-spring-were utilised by sheep and-deer, but secondary stems produced in summer were poorly grazed. Medium grazing (100-150 mm stem stubble) of chicory gave a reasonable compromise between total production and feed quality. There was a large decrease in plant density in November-December, which was unrelated to grazing intensity, that requires further study.

Keywords: Cichorium intybus, grazing intensity, growth rate, plant density, Puna chicory, reproductive growth.

Introduction

Puna chicory (Cichorium intybus L.) has been widely adopted as a specialist feed in recent years. A major attribute of Puna chicory is its high growth rate in late spring and summer (Hare et al. 1987). Puna chicory has been reported to have high daily growth rates in excess of $150 \mathrm{~kg} \mathrm{DM} / \mathrm{ha}$ per day (Matthews et al. 1990) and total forage yields up to $25 \mathrm{t} \mathrm{DM} / \mathrm{ha}$ from December to May in favourable conditions (Hare et al. 1987). These high growth rates are driven by reproductive growth that culminates in the production of stems up to $2 \mathrm{~m}$ tall unless the crop is grazed (Rumball 1986). A difficulty with the grazing management of Puna chicory is maintaining a balance between control of the reproductive stems, which have poor digestibility (Clark et al. 1990), and maximising leaf production without prejudicing the persistency of the crop. The current recommendation is to rotationally graze Puna chicory to $30-50 \mathrm{~mm}$ at 4 - to 5-week intervals in spring (Clark et al. 1990; Hare et al. 1990), but there is a poor understanding of the effect of reproductive stem removal on plant growth and development. The objective of this research was to examine the influence of the height of stem remaining after grazing on subsequent leaf and stem growth, and on plant survival.

\section{$M$ aterials and methods}

The field experiments were located on the Deer Research Unit (DRU) and the Pasture and Crop Research Unit (PCRU), on Tokomoru silt loam soil (Typic Fragiaqualt), at Massey University. The Grasslands Puna chicory was 2 years old on the DRU and 4 years old on the PCRU-and-was-grazed-by-deer-and-mature-age-ewes, respectively. Before chicory began to grow, Gramoxone at 3 litres/ha was used to kill all the grasses on the PCRU. Three nitrogen applications at $37 \mathrm{~kg} \mathrm{~N} / \mathrm{ha}$ each time were made on the DRU in early spring, late spring and early autumn respectively and one nitrogen application of $20 \mathrm{~kg} \mathrm{~N} / \mathrm{ha}$ was applied on the PCRU during spring. The grazing intervals for the different grazing intensities on the PCRU were 3 weeks between grazings up to January, and 5 weeks between grazings from January onwards. The four grazing intensities used at each grazing on the PCRU were very hard (stem grazed to ground level O-50 mm), hard (50-100 mm stem stubble), medium (100-150 mm) and lax (150$200 \mathrm{~mm}$ ). The medium grazing (down to $100-150 \mathrm{~mm}$ stem stubble) was also used in the rotational grazing regime on the DRU.

The treatment plots were $288 \mathbf{m}^{\mathbf{2}}$ and there were 4 replicates in a Latin square design on the PCRU. On the DRU, eight 0.5 ha plots were used in the rotational grazing regime, but only four of them were used as replicates.

The first grazing was when the reproductive stem began to elongate, which was in October on the DRU 
and in November on the PCRU. The phenological development of chicory on the DRU was about one month earlier than on the PCRU. On the DRU, 23 deer, equivalent to 46 deer/ha, rotationally grazed each plot, and the duration of grazing was between 5-7 days, depending on the growth rate of chicory. On the PCRU, about 15-20 sheep, equivalent to 520-695 sheep/ha, were used in each plot for 1-2 days, depending on the grazing intensities. The grazing intensities were controlled by grazing time. Once the desirable height was reached, the sheep were moved out of the plot. Grazing finished on 27 May 1994 on the DRU and on 4 May 1994 on the PCRU. In January, the old stubble in each plot was trimmed by mowing $(80-100 \mathrm{~mm})$ after grazing on the DRU. On the PCRU all the plots were mowed after the fourth grazing, on 7 January, to clear the uneaten stubble and docks. The mowing heights were 30, 70, 120 and $170 \mathrm{~mm}$ for the very hard, hard, medium and lax grazing treatments respectively.

Plant densities were monitored on each site after grazing in both randomised and permanent quadrats $(50 \mathrm{~mm} \times 50 \mathrm{~mm})$. Herbage mass was measured in the quadrats on the PCRU by cutting to ground level before and after each grazing. The material was then dissected into green leaf, stem, weeds and dead materials. On the DRU the individual plants in the quadrats were separated into primary leaf and stem, secondary leaf and stem, and axillary leaf and stem. Plant height and regrowth sites (bud numbers) were also observed on both sites.

All the data were analysed with the General Linear Model (GLM) in the SAS programme. Plant density and shoot number per plant were also analysed by repeated measures.

\section{Results}

\section{Herbage accumulation}

The weather during 1993-1994 was very dry, especially in summer. The total rainfall from October 1993 to April 1994 was $375 \mathrm{~mm}$, which was $67 \%$ of the lo-year mean. The rainfall in January and in February was only $33 \%$ and $19 \%$, respectively, of the lo-year mean (26 vs $79 \mathrm{~mm}$ and 13 vs $67 \mathrm{~mm}$ ).

Herbage accumulations of leaf and stem dry matter over the 181 days from 5 November to 5 May on the PCRU are shown in Table 1. The very hard grazing accumulated the highest leaf mass, $3967 \mathrm{~kg}$ DM/ha, and the least stem mass, $420 \mathrm{~kg} \mathrm{DM} / \mathrm{ha}$, while the lax grazing gave the highest stem accumulation (2114 kg $\mathrm{DM} / \mathrm{ha}$ ), which was significantly higher than for any of the other grazing treatments $(\mathrm{P}<0.01)$. There was a significant difference between leaf accumulation under very hard and hard grazing $(\mathrm{P}<0.01)$, but no significant differences between very hard, medium and lax grazing.
Table 1 Herbage accumulation of leaf and stem dry matter $(\mathrm{kg}$ DM/ha) over 181 days from 5 Nov to 5 May.

\begin{tabular}{|c|c|c|}
\hline Grazing intensity & Leaf & Stem \\
\hline & \multicolumn{2}{|c|}{ 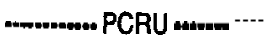 } \\
\hline Very hard $(0.50 \mathrm{~mm})$ & 3967 & 420 \\
\hline Hard $(50-100 \mathrm{~mm})$ & 2602 & 627 \\
\hline Medium $(100-150 \mathrm{~mm})$ & 3546 & 1356 \\
\hline $\operatorname{Lax}(150-200 \mathrm{~mm})$ & 3221 & 2114 \\
\hline SEM & \pm 238 & \pm 200 \\
\hline \multirow[t]{2}{*}{$\mathrm{LSD}_{0.05}$} & 674 & 567 \\
\hline & \multicolumn{2}{|c|}{ י.... } \\
\hline Medium (100-I 50 mm) & 5665 & 4342 \\
\hline SEM & \pm 282 & \pm 537 \\
\hline $\mathrm{LSD}_{0.05}$ & \multicolumn{2}{|c|}{429} \\
\hline
\end{tabular}

Puna chicory on the DRU accumulated 5665 and $4342 \mathrm{~kg} \mathrm{DM} / \mathrm{ha}$ for leaf and stem respectively during the same period. The total herbage accumulation on the DRU was 10,007 $\mathrm{kg}$ DM/ha, which was twice as much as that on the PCRU under a similar grazing intensity.

\section{Growth rate}

Growth rates of leaf and stem were significantly influenced by grazing intensities before early January $(\mathrm{P}<0.01)$, but after this time there were no significant responses to grazing intensity except, for leaf growth rate under lax grazing $(P<0.05)$ (Figure 1). The very hard grazing gave the highest leaf growth rate and the least stem growth rate before early January compared with the other grazing treatments. The lax grazing had the highest leaf growth rate after early January. During spring, lax grazing once greatly suppressed the stem growth rate, and the very hard and hard grazing intensities totally controlled primary reproductive stem growth. Stem growth rate under lax grazing decreased from $67.4 \mathrm{~kg} \mathrm{DM} / \mathrm{ha}$ in mid November to $16.7 \mathrm{~kg} \mathrm{DM} /$ ha in early January. Stem growth rates under very hard and hard grazing were less than $1.0 \mathrm{~kg} \mathrm{DM} / \mathrm{ha}$ through the rest of the season.

\section{Growth pattern of different plant parts (DRU)}

Figure 2 shows the growth rate of different parts of the chicory plant under the medium grazing management (rotational grazing to $100-150 \mathrm{~mm}$ stubble) on the DRU. Grazing sharply decreased the growth rates of the primary leaf and stem during early spring. Growth rate of primary leaf decreased from $29.7 \mathrm{~kg} \mathrm{DM} / \mathrm{ha}$ in October to $0.6 \mathrm{~kg} \mathrm{DM} / \mathrm{ha}$ in December, while growth rate of stem decreased from 46.5 to $2.3 \mathrm{~kg} \mathrm{DM} / \mathrm{ha}$ during the same period. After December, the growth rates of primary leaf and stem were never over $5.0 \mathrm{~kg}$ DM/ha. However, secondary and axillary leaves and 
Figure 1 Growth rate dynamics on the PCRU (the vertical bar shows LSD,,).
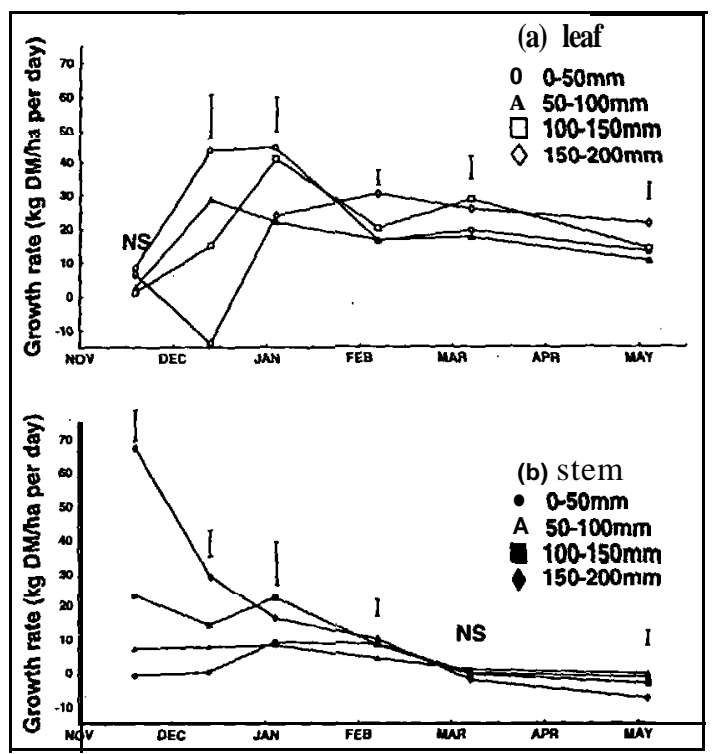

stems started to grow after grazing stopped primary leaf and stem growth. After reaching their peaks in December, secondary leaf growth rate remained relatively constant throughout the rest of the season, but secondary stem growth rate quickly declined. The decline in secondary_stem-growth-rate-in-January= February was at least partly due to trimming (80-100 $\mathrm{mm})$ after grazing.

\section{Leaf and stem consumption}

Figure 3 shows that most of the leaves were being grazed throughout the growing season. Before December $70 \%$ of primary stem was grazed. Therefore, the stems produced during spring were utilisable. After December the old primary stems and the secondary stems were largely ignored by animals. In February, the percentage of stem grazed was only 25\%; In autumn some secondary shoots produced new stem again and there was a flush of new shoots (Figure 4b). As a consequence the percentage of grazed stem increased.

Plant density and plant size

Plant density was unaffected by the level of grazing intensity on the PCRU but it decreased at both sites $(\mathrm{P}<0.05)$, especially after the primary stem stopped growing in November on the DRU and in December on the PCRU (Figure 4). Plant density declined to its lowest point in February on both the DRU and the PCRU. The minimum plant density of 69 and 19 plants
Figure 2 Growth rate dynamics on the DRU (the vertical bar shows $\operatorname{LSD}_{0.05}$ ).

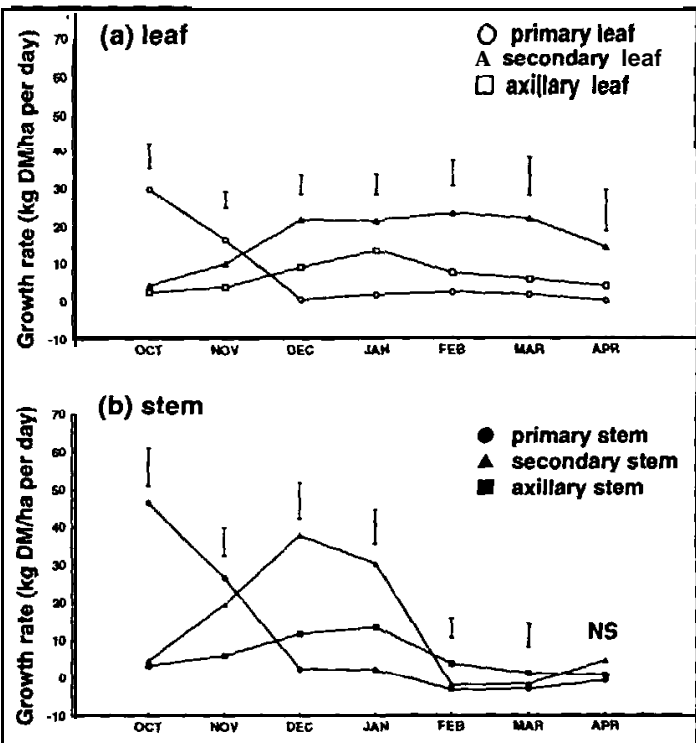

(c) total

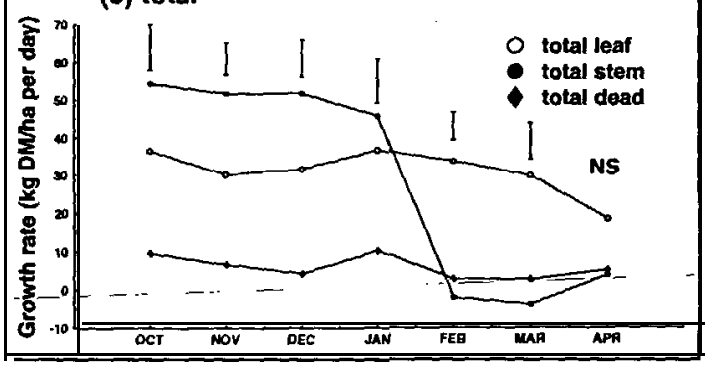

Figure 3 Percentage of leaf and stem grazed on the DRU (the vertical bar shows $\mathrm{LSD}_{0.05}$ ).

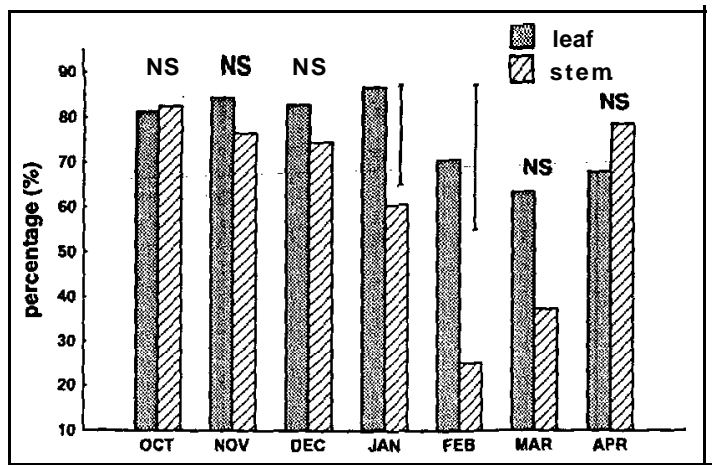

per $\mathbf{m}^{2}$ on the DRU and the PCRU respectively represented a $41 \%$ and $27 \%$ decrease compared with the densities in November. However, the shoot numbers per 
plant had doubled on the PCRU and tripled on the DRU by autumn compared with in spring. Shoot numbers per plant on the PCRU were 3 times those on the DRU.

Figure 4 Plant densities and plant sizes on the DRU and the PCRU.

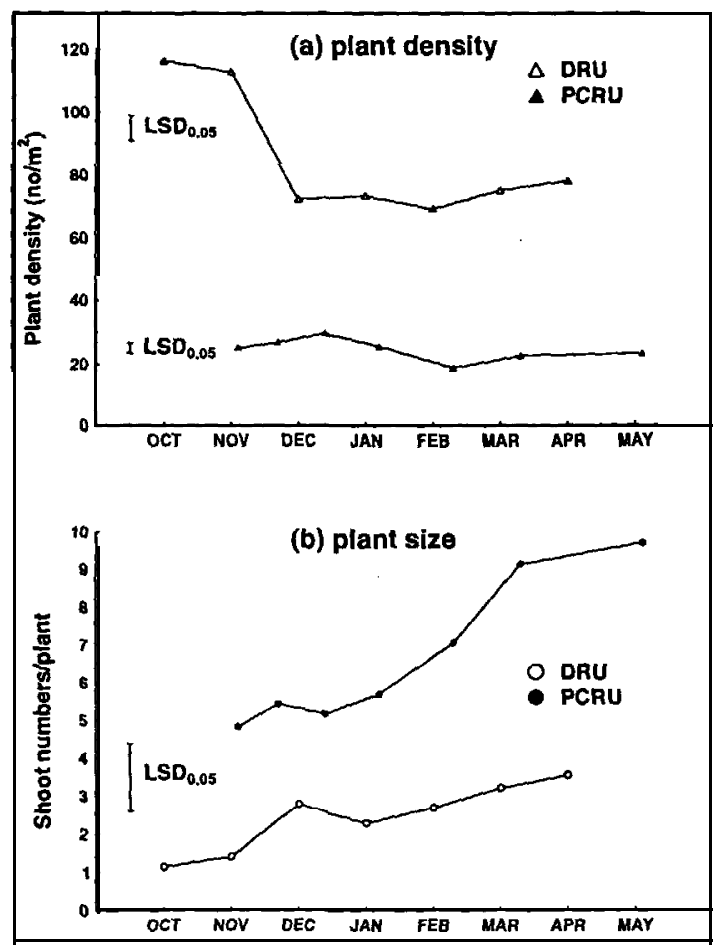

The shoot number per $\mathbf{m}^{2}$ was similar for the two sites $\left(183 \pm 12\right.$ shoots per $\mathrm{m}^{2}$, Figure $\left.4 \mathrm{a}, \mathbf{4 b}\right)$. Shoot number per $\mathrm{m}^{2}$ increased $77 \%$ and $67 \%$ from February to April on the PCRU and the DRU respectively.

\section{Discussion}

The growth of the primary reproductive stem was greatly suppressed by grazing intensities that left less than $100 \mathrm{~mm}$ of stem stubble. Although hard grazing suppressed primary stem growth, it increased leaf growth rate until January. After January leaf growth rate was the greatest under lax grazing due to the greater secondary and axillary shoot growth resulting from the higher primary stem stubble. However, suppression of the primary reproductive stem under hard grazing failed to prevent the production of secondary and axillary reproductive stems. Although there were few second phase reproductive stems on the hard grazed plants all shoots were reproductive until autumn. This suggested that the buds released for growth by removal of the apical dominance effect of the primary stem were all vernalised during winter, that is, grazing management can decrease reproductive stem production but not prevent it.

Utilisation of primary reproductive stem by both deer and sheep was similar to utilisation of leaf in spring. Digestibility of primary stem is lower than that of leaf (Clark et al. 1990), but the greater stem growth under medium and lax grazing resulted in a greater total herbage accumulation compared with hard and very hard grazing. The utilisation of the secondary and axillary reproductive stems produced from January to March was very low compared with that of leaf. Animals were observed to eat only the soft buds on the stems. Therefore, over the growing season, while leaf production was similar in all treatments total herbage accumulation was greater in the laxer grazed treatments, but the quality of the feed was lower. It is also possible that until they were mowed, the secondary stems hindered stock access to leaves.

Shoot number per plant increased throughout the season. There was a noticeable flush of vegetative shoots in late autumn (April-May) which were highly utilised by stock. Presumably these vegetative shoots develop late in the growing season each year but the timing of the flush was probably determined by the onset of autumn rain after the dry summer. These vegetative shoots require further study, particularly their survival through winter.

Shoot number per plant was greater on the PCRU than the DRU as would be expected due to the lower plant density on the PCRU. Shoot number per unit area was similar on the PCRU and the DRU but herbage mass accumulation was approximately twice as great on the DRU despite the close proximity of the two sites. The herbage production on both sites was affected by the dry summer (the total rainfall in January and February was only $39 \mathrm{~mm}$ in 1994). Nevertheless, the herbage yields reported for chicory, up to $25 \mathrm{t} \mathrm{DM} / \mathrm{ha}$, are also dependent on the degree to which stem growth is controlled (Hare et al. 1987; Matthews et al. 1990). Hare et al. (1987) harvested the herbage from a seed production crop while $90 \%$ of the maximum herbage yield reported by Matthews et al. (1990) was stem.

The chicory plant density on the DRU decreased by about $40 \%$ in November-December. This decrease coincided with the cessation of primary stem growth, but there was no effect of grazing intensity on plant density in the PCRU trial. Although the cause of the decline in plant density in early summer was not apparent, this decline will shorten the productive life span of the crop and requires further study.

In conclusion, the primary reproductive stem growth of chicory was controlled by grazing, but 
secondary reproductive stem was not due to its poor palatability. Leaf growth rate was greater early in the season under hard grazing, and late in the season under lax grazing. Overall, medium grazing $(100-150 \mathrm{~mm}$ stem stubble) represented a reasonable compromise between total herbage production and feed quality.

\section{ACKNOWLEDGEMENTS}

We thank Terry Lynch, Mark Osborne, Gary Evans and Bryan Sturgess for their technical assistance in the field.

\section{REFERENCES}

Clark, D.A.; Anderson, C.B.; Berquist, T. 1990. Growth rate of 'Grasslands Puna' chicory (Cichorium intybus L.) at various cutting intervals and heights and rates of nitrogen. New Zealand journal of agricultural research 33: 213-217.

Hare, M.D.; Rolston, M.P.; Crush, J.R.; Fraser, T.J. 1987. Puna Chicory - a perennial herb for New Zealand pastures. Proceedings Agronomy Society of New Zealand 17:45-49.

Hare, M.D.; Rowarth, J.S.; Archie, W.J.; Rolston, M.P.; Guy, B.R. 1990. Chicory seed production: research and practice. Proceedings of the New Zealand Grassland Association 52: 91-94.

Matthews, P.N.P.; Kemp, P.D.; Austin, G.M. 1990. The effect of grazing management on the growth and reproductive development of chicory. Proceedings Agronomy Society of New Zealand_20:41_43.

R̄umball, W. ' $\overline{986}$. 'Grasslands Puna' chicory (Cichorium intybus L.). New Zealand journal of experimental agriculture 14: 105-107. 